1 Article Type: Original Article

2

\title{
CLIMATIC, VEGETATION AND EDAPHIC INFLUENCES ON THE PROBABILITY OF FIRE ACROSS MEDITERRANEAN WOODLANDS OF SOUTH EASTERN AUSTRALIA
}

Running heading: Time since fire and fire probability in mallee woodlands and heathlands Rebecca K. Gibson ${ }^{1}$, Ross A. Bradstock ${ }^{1}$, Trent Penman ${ }^{1}$, David A. Keith ${ }^{2,3,4}$, Don A. Driscoll $^{5}$

1) Centre for Environmental Risk Management of Bushfires, Institute for Conservation Biology and Environmental Management, University of Wollongong, NSW 2522, Australia, gibson.rebecca@gmail.com, rossb@uow.edu.au, tpenman@uow.edu.au

2) NSW Office of Environment and Heritage, 43 Bridge Street, Hurstville, NSW 2220, Australia, David.Keith@environment.nsw.gov.au

3) Australian Wetlands, Rivers and Landscapes Centre, University of New South Wales 2052, Australia.

4) Long Term Ecological Research Network, Terrestrial Ecosystem Research Network, Australia.

5) ARC Centre of Excellence for Environmental Decisions, the NERP Environmental Decisions Hub, Fenner School of Environment and Society, The Australian National University, Canberra ACT 0200, Australia. Fenner School of Environment and Society, Australian National University, Canberra, ACT 0200, Australia, Don.Driscoll@anu.edu.au Corresponding author: Rebecca Gibson: phone (61) 2 42215531; fax (61) 2 42215395; email gibson.rebecca@gmail.com

Keywords: Bayesian modelling, fire interval, mallee woodlands, Mediterranean climate region, productivity gradient, Weibull distribution.

5 Word count (Abstract): 297

6 Word count (Body): 6577

7 No. References: 53

28 Page estimate for figures/tables: 6 


\section{Abstract}

30 Aim:

31 We investigated how the probability of burning is influenced by time since fire (TSF) and gradients of climate, soil and vegetation in the fire-prone Mediterranean-type climate mallee woodlands of south eastern Australia. This provided insight into processes controlling contemporary fuel dynamics and fire regimes across biogeographic boundaries, and consequent effects of climate change on potential shifts in boundaries between fuel systems and fire regimes, at a sub-continental scale.

\section{Location:}

38 South eastern Australia.

39 Methods:

40 We used a Bayesian framework to examine the effects of combinations of rainfall, vegetation and soil type on the hazard of burning and survival parameters of the Weibull distribution.

42 These analyses identified the nature of environmental controls on the length of fire intervals and the age-dependence of the hazard of burning.

\section{Results:}

45 Higher rainfall was consistently associated with shorter fire intervals. However, within a 46 single level of rainfall, an interaction between soil and vegetation type influenced the length 47 of fire intervals. Higher fertility sands were associated with shorter fire intervals in grassdominated communities, while lower fertility sands were associated with shorter fire intervals in shrub-dominated communities. The hazard of burning remained largely independent of TSF across the region; only in shrub-dominated communities at high rainfall did the hazard of burning markedly increase with TSF.

\section{Main conclusions:}

53 Rainfall had a dominant influence on fire frequency in the Mediterranean climate mallee woodlands of south eastern Australia. Predicted changes in the spatial distribution and amount of rainfall therefore have the potential to drive changes in fire regimes. However, the effects of soil fertility and rainfall on fire regimes do not align on a simple productivity gradient. Reduced soil fertility may favour plant traits that increase rates of woody litter fuel accumulation and flammability, which may alter the over-riding influence of rainfall gradients on fire regimes. 
Fuel dynamics and resultant fire regimes may change in the future due to global change, but the nature of these changes are poorly understood (Matthews et al., 2012). Higher atmospheric $\mathrm{CO}_{2}$ and changes to temperature and precipitation as a result of climate change may influence plant growth and consequent fuel dynamics, but such changes will vary across regions and among plant species (Lenihan et al., 2008; Pausas \& Paula, 2012). A fundamental understanding of how fuel dynamics can influence contemporary fire regimes is needed to predict how fire regimes may respond to global change and to management practices such as fuel treatment (Bradstock et al., 2012; Matthews et al., 2012; King et al., 2013).

The influence of fuel accumulation on fire regimes can be inferred from the nature of hazard functions (McCarthy et al., 2001). These functions relate the instantaneous probability of burning to the post-fire age of the fuel complex, which can be estimated by time since fire (TSF) in landscapes. In systems where fire is dependent on fuel age, the probability of fire in young fuels is likely to be low and increase over time if fuels accumulate in a regular manner. By contrast, in systems where fire is independent of fuel age, the probability of fire is unrelated to TSF. This could arise in systems where irregular events, such as periods of high rainfall, promote fire through a rapid response of ephemeral vegetation to suitable conditions (McCarthy et al., 2001; Pausas \& Paula, 2012). These examples indicate contrasting types of fuel dynamics, where, respectively, fuel may or may not accumulate with TSF. Models of the probability of burning with TSF for a given system can be used to characterise patterns of fire interval distributions and quantify the role of TSF in determining fire regimes (McCarthy et 84 al., 2001).

Moisture and soils will influence vegetation community structure and composition, which in turn may influence the probability of fire. For example increased productivity, as a function of increasing moisture, is often associated with increased fire frequency (i.e. the productivityfire frequency model; Bond \& Keeley, 2005; Pausas \& Bradstock, 2007; Krawchuk \& Moritz, 2011; Gibson et al., 2014). While considerable attention has been devoted to the influence of climatic moisture on fire occurrence (Bond \& Keeley, 2005; Pausas \& Paula, 
fertility) may influence this relationship. For example, lower soil fertility at any given level of rainfall may increase the cover of woody plant with sclerophyllous leaves, increasing the flammability of vegetation (Keeley et al., 2011; Lehmann et al., 2011; Gibson et al., 2014). Soil type therefore may play a role, in interaction with moisture, in determining fuel types and resultant fire probability.

Gradients in rainfall, vegetation and soil in southern Australia can be used to examine the effect of differing fuel systems on the probability of burning (e.g. O'Donnell et al., 2011a). In arid ecosystems of southern Australia, the fuel system is dominated by ephemeral herbage and grasses that respond rapidly to infrequent and sporadic periods of heavy rainfall. As a result, fire frequency is relatively low (Allan \& Southgate, 2002; Letnic \& Dickman, 2006). In temperate sclerophyllous shrublands, woodlands and forests near the coast in southern Australia, spatially continuous surface litter fuels accumulate in a regular manner and fire occurs more frequently than in arid climates (Gill \& Catling, 2002; Russell-Smith et al., 2007; Bradstock, 2010). Mallee communities in the Mediterranean-type climate region of south eastern Australia occupy a transitional zone between these contrasting ecosystems and fuel types.

Previous research in the Mediterranean-type climate region of south eastern Australia indicated that area burned and fire frequency were positively correlated with rainfall along a north to south gradient of woodland and shrubland vegetation types situated on oligotrophic, aeolian-derived sandy soils (Pausas \& Bradstock, 2007). These trends in fire possibly correspond with a transition in vegetation composition and structure from dominance of the understory by grasses to dominance by shrubs as rainfall increases (Krawchuk \& Moritz, 2011; Gibson et al., 2014). Thus a corresponding shift in fire regime characteristics could be anticipated in response to this change in the nature of surface fuel along the rainfall gradient. However, possible effects of rainfall are partially confounded by the low fertility of the sandy substrates on which these woodlands and shrublands are situated (Blackburn \& Wright, 1989). Such a trend in soil fertility has the potential to reduce productivity (Paoli et al., 2008), favour woody, sclerophyllous species (Mills et al., 2012) and alter resultant effects of rainfall on fire regimes. 
124 In this study we investigated how fire probability and fire intervals responded to gradients of

125 climate and variations in soil and vegetation attributes in the Mediterranean-type climate 126 woodlands ("mallee" vegetation, Noble \& Bradstock, 1989) of south eastern Australia. We

127 used fire history data for the region to test the prediction that the probability of burning would 128 become more frequent as rainfall increases. We also examined how the relative abundance of 129 grass and woody shrub components and sand types of differing fertility may alter the over130 riding influence of rainfall on fire regimes. We predicted that fire probability would be more 131 dependent on TSF in mallee communities with a prominent shrub layer and on low fertility 132 sands (i.e. dominance of woody litter fuels) than communities with a grassy understory and 133 those situated on higher fertility sands.

\section{MATERIALS AND METHODS}

\section{Study Area}

136 The study was carried out in two Mediterranean-type climate regions in south eastern 137 Australia (Fig. 1); i) the Murray Lowlands from south-west New South Wales (NSW), to 138 central-west Victoria; ii) the Eyre Peninsula, including Kangaroo Island in South Australia. 139 These regions span wide rainfall gradients $(\approx 200-600 \mathrm{~mm} / \mathrm{yr})$ and a variety of vegetation 140 types (ANVA, 2001) including mallee woodlands and mallee heathlands. Mallee woodlands 141 are extensive in the north of each region (200-350mm/year). This vegetation type is 142 dominated by shrub-like, multi-stemmed Eucalyptus species (i.e. mallee growth habit; 143 Burbidge, 1950), with an understory containing perennial hummock grasses (Triodia sp.), 144 along with sclerophyllous shrubs, such as species of Acacia, Beyeria, Chenopodium, 145 Dodonea, Eremophila, Halgania, Leptospermum and Westringia; (Westbrooke et al., 1998).

146 Ephemeral grasses and herbs become abundant following periods of heavy rainfall (e.g. 147 Austrostipa sp., Zygophyllum sp.). Mallee heathlands, dominated by multi-stemmed 148 Eucalyptus spp. are extensive across the south of the study area $(350-600 \mathrm{~mm} / \mathrm{yr})$ with a 149 relatively dense understory dominated by sclerophyllous shrubs (e.g. species of Acacia, 150 Baeckea, Eremophila, Grevillea, Leucopogon, Templetonia and Melaleuca). Hummock and 151 ephemeral grasses are sparse or absent in this community (Bradle, 2010). Along with changes in mean annual rainfall, seasonality of rainfall changes across the study region from semi-arid in the north, where rainfall and plant growth are not strongly seasonal, to a more temperate, 
154 Mediterranean-type climate with peaks of growth in winter and spring (Hutchinson et al. 155 2005).

157 Mallee woodlands and mallee heathlands occur on undulating dune fields of aeolian sands that are either solonised brown earths (red sands) or solodised solonetz (yellow sands)

159 (NRIC, 1991). The red sands are alkaline with poor to moderate fertility and commonly 160 support semi-arid mallee, while the yellow sands are relatively more acidic, less fertile and

161 more coarse than the red sands and commonly support temperate mallee heathlands 162 (Blackburn \& Wright, 1989). The characteristics and distribution of these contrasting sand 163 types reflects differences in origin; red sands derived from alluvial and subsequent Aeolian 164 origins are prevalent in the north of both study regions, whereas yellow sands formed by marine processes are common in the south (Wasson, 1989). Mallee woodlands occur mainly on red sands in the drier north (Table 1), while mallee heathlands occur mainly on yellow sands across the wetter south (Table 1). However, there are more limited instances where mallee woodlands occur on yellow sands and where mallee heathlands occur on red sands 169 (Table 1).

\section{Data compilation}

171 Approximately 6300 points, spaced at a minimum of $1 \mathrm{~km}$ apart, were randomly generated 172 and used as sampling points in conservation reserves across the study area, totalling $17353,366 \mathrm{~km}^{2}$ (see Fig. S1-S9, Appendix S1), using Hawth's Tools in ArcGIS 9.2. At each 174 point, the length of fire intervals, average annual rainfall, vegetation and soil type were estimated. Data sampling was constrained within large tracts of native vegetation situated within national parks and conservation reserves (Fig. 1).

178 Fire interval data were determined by overlaying fire history maps, obtained from state 179 government agencies; New South Wales Office of Environment and Heritage, (NSW OEH), 180 Victorian Department of Sustainability and Environment (Vic DSE), and South Australian 181 Department of Environment, Water and Natural Resources (SA DEWNR). The spatial resolution of fire history data varies, due to different methods of data capture (e.g. satellite imagery, GPS and hand drawn maps). The first recorded fires in the Victorian and South

184 Australian database occurred in 1932, while in NSW the first recorded fires occurred in 1935. 185 However, the completeness and accuracy of the fire history record in each state is considered 
186

187

188

189

190

191

192

193

194

195

196

197

198

199

200

201

202

203

204

205

206

207

208

209

210

211

212

213

214

215

216

217

more reliable from 1970 (see Fig. S10-S18, Appendix S2). For the Murray Lowland region, fire history data derived from satellite imagery interpreted by the Mallee Fire Group at LaTrobe University was used, with a minimum spatial resolution of 50m (Haslem et al., 2011). The years of wildfire occurrence that intersected each random sampling point were ordered chronologically, and the length of the intervals between fires were calculated. Prescribed burns were excluded from the analysis as these fires represented a negligible component of total burn area $(<1 \%$ of the burnt area in any given year) and tend to have greater patchiness and uneven coverage within the mapped fire scar, compared to wildfires. At a small portion of points, the fire intervals could therefore be overestimated.

Intervals bounded by a fire of unknown date (i.e. either because the period of observation began after the previous fire occurred or terminated before the next fire occurred) are considered 'censored' intervals or incomplete data (Polakow \& Dunne, 1999; Moritz et al., 2009). Estimates of fire return interval vary widely depending on whether censored data are included or not (Kraaij et al., 2013). For example, if censored data are excluded from such analyses, the length of fire intervals will be generally underestimated (Moritz et al., 2009; O'Donnell et al., 2011a; Kraaij et al., 2013). O’Donnell et al., (2011a) noted that exclusion of censored data would effectively result in a study that was confined to a subset of samples that were relatively frequently burnt resulting in inaccurate characterisation of fire regimes for the entire study domain. Alternatively, Fernandes et al., (2012) argued that analyses based on uncensored data may provide a more accurate depiction of fire recurrence and risk in those areas inherently more prone to burning.

Our initial exploratory analyses, using only uncensored data, confirmed this bias (authors' unpublished results). Thus analyses using censored data were warranted based on the general principle that inclusion of censored data, and resultant estimated intervals, would provide a more thorough characterisation of the fire regime. Our study also builds on the precedent for use of censored data in past studies in temperate, shrub-dominated Mediterranean climate landscapes (e.g. Moritz et al., 2009; Kraaij et al., 2013), including examples such as O’Donnell et al., (2011a) with strong floristic, edaphic and climatic affinities to our study area. 
218 Approximately $73 \%$ of all fire intervals included in the dataset were censored (i.e. minimum

219 estimates of fire intervals), with $27 \%$ of fire intervals bounded by known dates (i.e. measured

220 intervals). However, the distribution of censored data was uneven across the study area with

221 mallee heathlands and mallee woodlands having relatively low and high proportions,

222 respectively, of censored data (Table 2). Inclusion of censored data in analyses therefore

223 eliminated biases arising from unequal proportions of censored data within the study area

224 (e.g. major underestimation of fire intervals in mallee woodlands; Table 2), if only

225 uncensored data was used. The minimum possible fire-interval was therefore estimated on

226 this basis (i.e. the time between the year of fire and the beginning or end of the records).

228 Rainfall, vegetation and soil data at each point were estimated using the enumeration function of Hawth's Tools. Average annual rainfall across the study area was determined using the spatial map of ANUCLIM version 6.0 (Hutchinson, 2004), which estimates a mean annual precipitation surface for Australia based on weather station records from 1975 to 2005. As an alternative to rainfall we considered using an ANUCLIM moisture index which incorporates evaporation. The average annual moisture index, mean moisture of the high quarter and mean moisture of the low quarter were all found to be highly correlated with mean annual precipitation $(\mathrm{P}<0.0001, r>0.8)$. As a result rainfall rather than the moisture index was used in the analyses on the basis of simplicity, as recommended by Wintle et al., (2005).

238 Vegetation mapping was obtained from the relevant state government agencies (unpublished data from the NSW OEH, Vic DSE, and SA DEWNR). Vegetation types that were included in the analysis were either mallee woodlands or mallee heathlands. Soil mapping was obtained from the digital Atlas of Australian Soils (Bureau of Rural Sciences, 1991). Soil types that were included were categorised as either red (including brown) or yellow (including pale coloured) siliceous sands. These datasets had a minimum spatial resolution of 250 metres.

246 Spatial autocorrelation was tested for using the Moran's I spatial autocorrelation to ensure the 247 assumption of independence of sampling points could be maintained (Legendre, 1993). 248 Moran's $I$ values range from -1 (dispersion) to +1 (clustering), with values close to zero 249 indicating a random spatial pattern (Diniz et al., 2003). Moran's I values were calculated for 
250 fire interval data for the sampling points within each park across the study area (15 parks in total). To maximise the sample size while minimising the effects of spatial autocorrelation, points were selected to be a minimum of $1 \mathrm{~km}$ apart to maintain Moran's $I$ values of $<0.2$.

\section{Statistical Analysis}

255 The generalised Weibull distribution has been extensively used in fire-interval analyses (Johnson \& Gutsell, 1994; O'Donnell et al., 2011a). The cumulative mortality function of the Weibull distribution, $F(t)$, represents the probability that a fire will have occurred at or before time ' $\mathrm{t}$ ' and takes the form:

$$
F(t)=\operatorname{Pr}(T \geq t)=1-e^{-(t / b)^{\wedge} c}
$$

where $\mathrm{T}$ denotes the time or interval at which a fire occurs, $t$ is time since the last fire in years, $b$ is the Weibull scale parameter and $c$ is the Weibull shape parameter. The hazard function, $\lambda(t)$, of the Weibull distribution represents the probability of burning with respect to TSF and takes the form:

$$
\lambda(t)=c t^{c-1} / b c
$$

where $t$ is time since the last fire in years, $b$ is the scale parameter and $c$ is the shape parameter. In both instances, the $b$ parameter is related to the expected length of fire interval that will be exceeded approximately $37 \%$ of the time and the $c$ parameter captures how the hazard of burning changes with TSF. When $c=1$, the hazard of burning does not change with time since fire, when $1<c<2$, the hazard of burning grows at a diminishing rate, and when $c=2$, the hazard of burning increases linearly with time (Johnson \& Gutsell, 1994; O'Donnell et al., 2011a). Given that censored data were included, values of $b$, the estimates of potential fire intervals were not measured intervals. High proportions of censored data also tend to increase the Weibull $b$ parameter (with wider CIs) and lower Weibull $c$ parameter close to zero (with narrower CIs) (Moritz et al., 2009).

We used a Bayesian framework with uninformative priors to test the effect of various models containing all additive combinations of the factors of rainfall, vegetation and soil type on the hazard and mortality parameters of the Weibull distribution (see Table 2). Interactive models were not considered due to degrees of freedom limitation. Bayesian models with uninformative priors are numerically similar to maximum likelihood models used for analyses of fire-interval information containing incomplete (censored) data (Polakow \& 
282 Dunne, 1999; O'Donnell et al., 2011a). We used Markov chain Monte Carlo (MCMC) 283 methods to calculate the model parameters (Spiegelhalter et al., 2002). To ensure the MCMC 284 was sampled from the posterior distribution, it was necessary to discard the initial samples in 285 the Markov chain. We initially considered 110,000 samples and discarded the first 10,000. 286 The Bayesian models were batch run in the OpenBUGS program, version 2.2.0 (Thomas et 287 al., 2006). We used the Deviance Information Criterion (DIC) (Spiegelhalter et al., 2002) to 288 assess the effects of differing explanatory variables on the fire parameters (response 289 variables). Models containing sets of explanatory variables with changes in DIC of greater 290 than 10 points of the best model were considered to have essentially no support (McCarthy, 291 2007). Within a model, we regarded parameter estimates as significant at the $P=0.05$ level 292 when the 95\% credible intervals (CIs) did not overlap zero. Similarly, significant differences 293 between parameter estimates were regarded when the 95\% CIs did not overlap (McCarthy, 294 2007).

\section{RESULTS}

296

297

298

299

300

301

302

303

304

305

306

307

308

309

310

311

312

The preferred model to explain variation in fire intervals with the most support contained all three explanatory factors; rainfall, vegetation and sand type. All remaining models had DIC values $>90$ points higher than the best model and thus were not considered further. All three predictor variables were included within the best model, as none of the 95\% CIs of their coefficients overlapped zero (Table 3 ).

The b-parameter estimate (the length of the fire interval that will be exceeded approximately $37 \%$ of the time) varied under each combination of soil, vegetation and rainfall (Table 3, Fig. 2, Fig. S19 Appendix S3). Higher rainfall was associated with shorter fire intervals in all soil and vegetation combinations. Fire intervals were significantly shorter with higher rainfall in each of the two dominant soil and vegetation combinations; red sand/mallee woodlands and yellow sand/mallee heathlands $(P<0.05$, Table 3, Fig. 2$)$.

Vegetation and soil type influenced the length of fire intervals in complex ways. Within a single level of rainfall and soil type, vegetation type had contrasting effects on the length of fire intervals. Mallee heathlands had significantly shorter fire intervals than mallee woodlands when on yellow sand (at 400 and 500mm/yr, $P<0.05$, Table 3, Fig. 2), whereas 
313 on red sand, mallee heathlands had significantly longer fire intervals than mallee woodlands

314 (at 300 and $400 \mathrm{~mm} / \mathrm{yr}, P<0.05$, Table 3, Fig. 2). Within a single level of rainfall and

315 vegetation type, soil type had contrasting effects on fire-intervals. Mallee heathlands on red

316 sands had significantly longer fire intervals than mallee heathlands on yellow sands at 400

317 and $500 \mathrm{~mm} / \mathrm{yr}$ (i.e. at 400 and 500mm/yr, $P<0.05$, Table 3, Fig. 2). By contrast, mallee

318 woodlands on red sands had significantly shorter fire intervals than mallee woodlands on

319 yellow sands at $400 \mathrm{~mm} / \mathrm{yr}(P<0.05$, Table 3, Fig. 2).

320

321 The complex interactions of rainfall, vegetation and soil type on the length of fire intervals

322 (b-parameter estimate) were reflected in the fire interval probability models. Increased

323 rainfall consistently increased the probability of fire occurring at or before a given time (Fig.

324 3). Higher rainfall also increased the hazard of burning, irrespective of TSF (Fig. 4). The

325 interaction of vegetation and soil type at any given level of rainfall influenced the probability

326 of fire, whereby lower soil fertility (i.e. yellow compared to red sands), corresponded with a

327 higher probability of fire in mallee heathlands, and a lower in the probability of fire in mallee

328 woodlands (Fig. 3). While this pattern occurred across rainfall levels, the effect was more pronounced at high rainfall (i.e. $400-600 \mathrm{~mm} / \mathrm{yr}$ ).

330

331 The c-parameter estimate (dependency of fire-intervals on TSF) was not significantly different among rainfall categories, but varied between the combinations of soil and vegetation (Table 3). Fire intervals were independent of fuel age in mallee woodlands on red sand $(c=1)$ and tended to be relatively more dependent on TSF in each of the other soil and vegetation combinations $(c>1)$. Fire intervals were significantly more dependent on TSF in yellow sand/mallee heathlands compared to red sand/mallee woodlands $(P<0.05$, Table 3$)$.

338 The hazard of burning remained largely independent of TSF in the majority of rainfall, vegetation and soil combinations (Fig. 4). There tended to be slight increases in the hazard of burning with TSF in each combination of vegetation and soil type at $>300 \mathrm{~mm} / \mathrm{year}$ rainfall, except for mallee woodlands on red sand. However, only in mallee heathlands on yellow sands at $500 \mathrm{~mm} /$ year did the hazard of burning increase with TSF, with an increase from $2 \%$ to $4 \%$ in the hazard of burning from 1 to 200 years since fire. 
DISCUSSION

346

347

348

349

350

351

352

353

354

355

356

357

358

359

360

361

362

363

\section{Productivity and fire regimes}

Rainfall had an overarching influence on fire frequency in the Mediterranean climate mallee woodlands of south eastern Australia. The length of the fire interval that will be exceeded approximately $37 \%$ of the time decreased with higher levels of rainfall, as predicted on the basis of general relationships between productivity and fire (Bond \& Keeley, 2005; Pausas \& Bradstock, 2007). In addition, higher levels of rainfall corresponded with in a change in the probability of fire with TSF. The probability of burning was independent of TSF in red sand/ mallee woodlands, which is dominant in the drier north of the region, but had a positive relationship with TSF in the yellow sand/ mallee heathlands, which dominates the wetter south. Such a response was consistent, as predicted, with an overall contrast between dominance of herbaceous fuels in the north to woody litter and foliage fuels in the south (Pausas \& Bradstock, 2007; Gibson et al., 2014), and a greater influence of TSF on the probability of burning due to patterns of litter fuel accumulation with time since fire.

Soil fertility also had a strong influence on the probability of fire, but the nature of this influence differed between vegetation types. Fire intervals in mallee woodlands were shorter compared with mallee heathlands on the relatively high fertility sands. In mallee heathlands fire intervals with a greater dependence on TSF at high rainfall $(>400 \mathrm{~mm} / \mathrm{yr})$ occurred on yellow sands with lower soil fertility. Therefore, the effects of soil fertility and rainfall on fire regimes did not align in terms of effects on potential productivity. This result indicates that models which attempt to predict large-scale fire patterns solely on the basis of moisture variations (e.g. Pausas \& Paula, 2012) are potentially subject to inaccuracy in regions with high variation in soil fertility. Integration of effects of different influences on 'productivity' is therefore needed to more completely understand its relationship with fire regimes.

A possible explanation for the complexity of the observed relationship is that the effect of soil fertility on the selection of plant traits and the corresponding influence on fire may override effects that ensue from the influence of rainfall on fire (e.g. lower soil fertility favours woody shrubs with small sclerophyllous leaves, increasing fire propensity; Ojeda et al., 2010; Keeley et al., 2011; Gibson et al., 2014). 
376 The overall trend toward longer intervals and lower hazard of burning with TSF (i.e. Weibull

$377 \quad b$ and $c$ parameters respectively) at low rainfall levels was most likely an outcome of the use

378 of high proportions of censored data in samples from low rainfall sites (Table 2). By contrast,

379 it was less likely that general trends in hazard of burning and fire intervals were influenced by

380 use of censored data, due to the more even spread of such data across the soil types (Table 2).

381 While conclusions concerning effects of rainfall were contingent on inclusion of censored

382 data we considered these to be robust, given the likelihood of major underestimation that

383 would have occurred if such data were excluded for low rainfall levels.

\section{Age dependency of burning and fuel systems}

385 Previous research within the mallee woodlands on red sand from $200-350 \mathrm{~mm} / \mathrm{yr}$ provided evidence that shrub cover increased while grass cover declined from north to south with increasing rainfall (Gibson et al., 2014). This change in the relative mix of grass and woody shrub cover with rainfall corresponds with a decrease in the length of fire-intervals (i.e. higher fire frequency, Fig. 2). There was no change in the dependency of fire intervals on TSF across this same range (i.e. within semi-arid mallee woodlands on red sand from 200$350 \mathrm{~mm} / \mathrm{yr}$; Fig. 4). Higher dependency on TSF at the wetter end of the gradient in these woodlands was expected but it was possible woody shrub cover at the wetter end remained insufficient to exert a TSF effect on fire intervals.

The strength of the TSF effect on fire in mallee heathlands on yellow sand was also weak. Other Mediterranean-type shrubland ecosystems have reported weak to moderate $\mathrm{c}$ parameter estimates (i.e. $c<2.5$; Moritz et al., 2004; O'Donnell et al., 2011a). In these systems, fuel most rapidly accumulates in the immediate post-fire period (e.g. $<10$ - 20 years). Beyond this time period fuel accumulation rate declines and the consequent influence of TSF on the probability of fire continues to diminish. Although there was an increase in the hazard of burning with TSF in yellow sand/mallee heathlands at high rainfall (Fig. 4), the magnitude of this effect was small (i.e. a maximum increase of $<4 \%$ on the hazard of burning). Most fires in mallee heathlands were likely to be more strongly influenced by the occurrence of extreme

404 fire weather and dry conditions in the antecedent year (i.e. low fuel moisture content) than by 405 the age and spatial patterns of fuels, as in other Mediterranean-type shrubland ecosystems 406 (Moritz et al., 2004; van Wilgen et al., 2010). In general, we note the lack of a strong effect 407 of TSF at high rainfall levels is a robust result, given that censored data was either absent or 
408

409

410

\section{Future implications}

412 Prescribed burning for hazard reduction is unlikely to be effective at reducing the probability 413 of fire, given that the probability of fire is unrelated to TSF in mallee woodlands and only 414

negligible across all plant community and soil types (Table 2). Compelling evidence of strong, implied effects of fuel accumulation on fire regimes in these shrub dominated systems is therefore lacking. weakly related to TSF in mallee heathlands on yellow sands. Historically most of the area burned in mallee woodlands of the Mediterranean region of southern Australia is due to a small number of fires that burn large areas (authors' unpublished data), which is consistent with reports in other crown-fire ecosystems around the world (Moritz, 1997; Johnson et al., 2001). In addition, the majority of fires in mallee woodlands have occurred shortly following extreme La Niña years (authors' unpublished data; Bradstock \& Cohn, 2002; O'Donnell et al., 2011b), which is likely to be due to the rapid response of ephemeral herbaceous fuels creating an increase in biomass available for burning. Therefore, strategic prescribed burning, particularly during periods following heavy rainfall, may provide critical fuel breaks to protect long unburnt vegetation in this community (Willson, 1999). Previous research in mallee woodlands of this region highlights the importance of the long-term development (i.e. $>100$ years) of some critical habitat resources, such as the mature canopy layer and tree hollows (Haslem et al., 2011). Therefore, fire management that protects long un-burnt mallee vegetation would also be advantageous for fauna habitat conservation.

Given the strong influence of rainfall on fire intervals in the Mediterranean region of south eastern Australia, changes in climate-related factors that are predicted to occur in the future have the potential to drive changes in fire regimes. For example, a $20 \%$ reduction in mean annual rainfall, which is in the range projected to occur in this region by 2070 (Suppiah et al., 2007), would correspond with an increase in mean fire intervals by approximately 15 years in yellow sand/mallee heathland and 64 years in red sand/mallee woodland. Temperatures are also likely to increase, possibly leading to a higher incidence of extreme fire weather, as evident in the study regions in the last few decades (Clarke et al., 2012). Such effects may ultimately lead to a decrease in mean fire intervals via an increase in area burned. 
439 Changes in temperature and moisture, as well as further increases in atmospheric $\mathrm{CO}_{2}$, may 440 affect different species in different ways. Warmer, drier conditions may provide a relative 441 advantage to plants that use the $\mathrm{C}_{4}$ photosynthetic pathway (Triodia sp.) compared to plants 442 that use the $\mathrm{C}_{3}$ pathway, such as woody shrubs and Austrostipa spp., the major contributors to 443 ephemeral fuels (Sage et al., 1999). As such, shifts in the patterns of fire intervals as a result 444 of changes in temperature and moisture may not be linear across the grass and shrub 445 dominated communities. Furthermore, elevated $\mathrm{CO}_{2}$ may be more beneficial to $\mathrm{C}_{3}$ plants 446 compared to $\mathrm{C}_{4}$ plants (Bond \& Midgley, 2012; Wang et al., 2012), which may ameliorate 447 any potential relative advantage of $\mathrm{C}_{4}$ plants under warmer, drier conditions. Given the 448 divergent effects of soil fertility on fire intervals in mallee woodlands (dominated by $T$. 449 scariosa plus ephemeral grasses following heavy rainfall) compared to mallee heathlands 450 (shrub dominated), elevated $\mathrm{CO}_{2}$ has the potential to interact with soil fertility to influence 451 the growth of grass and shrub species in different ways. Further research is required to 452 quantify the effects and interactions between moisture, temperature and $\mathrm{CO}_{2}$ and soil fertility 453 on the relative growth and abundance of the $\mathrm{C}_{4}$ grasses and $\mathrm{C}_{3}$ shrubs and grasses in this 454 region. This would provide important insight into potential consequences of climate change 455 on fuel dynamics and corresponding changes in fire regimes across the Mediterranean mallee 456 woodlands of south eastern Australia in the future.

457

\section{ACKNOWLEDGEMENTS}

459 The study was funded by an ARC Linkage grant (LP0776604) with Department of 460 Environment, Water and Natural Resources (SA) the Native Vegetation Council (SA), SA 461 Museum, and the Office of Environment and Heritage (NSW) as project partners. Thanks to 462 Dr Geoff Cary and Dr Mick McCarthy for providing advice on the analyses, and to Dr Brian 463 van Wilgen and Dr Joe Fontaine for providing comments on a draft of the manuscript. 
468

469

470

471

472

473

474

475

476

477

478

479

480

481

482

483

484

485

486

487

488

489

490

491

492

493

494

495

496

497

498

499

500

501

502

503

504

505

506

507

508

509

510

Allan, G.E. \& Southgate, R.I. (2002) Fire regimes in Spinifex landscapes. Flammable Australia (ed. by R.A. Bradstock, J.E. Williams and A.M. Gill), pp. 145-176. Cambridge University Press, Cambridge.

ANVA (2001) Australian Native Vegetation Assessment In. National Land and Water Resources Audit and Commonwealth of Australia, Canberra.

Blackburn, G. \& Wright, M.J. (1989) Soils. Mediterranean landscapes in Australia: mallee ecosystems and their management (ed. by I.R. Noble and R.A. Bradstock), pp. 35-53. CSIRO Australia, Melbourne.

Bond, W. \& Keeley, J. (2005) Fire as a global 'herbivore': the ecology and evolution of flammable ecosystems. Trends in Ecology and Evolution, 20, 387-394.

Bond, W.J. \& Midgley, G.F. (2012) Carbon dioxide and the uneasy interactions of trees and savannah grasses. Philosophical Transactions of the Royal Society B, 367, 601-612.

Bradle, R. (2010) A biological survey of the Eyre Peninsula, South Australia. In. Department of Environment and Heritage, South Australia.

Bradstock, R. (2010) A biogeographic model of fire regimes in Australia: contemporary and future implications. Global Ecology and Biogeography, 19, 145-158.

Bradstock, R.A. \& Cohn, J.S. (2002) Fire regimes and biodiversity in semi-arid mallee ecosystems. Flammable Australia: the fire regimes and biodiversity of a continent (ed. by J.W. Ra Bradstock, Am Gill), pp. 238-258. Cambridge University Press, Cambridge.

Bradstock, R.A., Cary, G.J., Davies, I., Lindenmayer, D.B., Price, O.F. \& Williams, R.J. (2012) Wildfires, fuel treatment and risk mitigation in Australian eucalypt forests: Insights from landscape-scale simulation. Journal of Environmental Management, 105, 66-75.

Burbidge, N.T. (1950) The significance of the mallee habit in Eucalyptus. Proceedings of the Royal Society of Queensland 62, 73-78.

Clarke, H., Lucas, C. \& Smith, P. (2012) Changes in Australian fire weather between 1973 and 2010. International Journal of Climatology, 33, 931-944.

Diniz, J.A.F., Bini, L.M. \& Hawkins, B.A. (2003) Spatial autocorrelation and red herrings in geographical ecology. Global Ecology and Biogeography, 12, 53-64.

Fernandes, P.M., Loureiro, C., Magalhaes, M., Ferreira, P. \& Fernandes, B. (2012) Fuel age, weather and burn probability in Portugal. International Journal of Wildland Fire, 21, 380-384.

Gibson, R.K., Bradstock, R.A., Penman, T., Keith, D.A. \& Driscoll, D.A. (2014) Changing dominance of key plant species across a Mediterranean climate region; implications for fuel types and future fire regimes. Plant Ecology, 215, 83-95.

Gill, A.M. \& Catling, P.C. (2002) Fire regimes and biodiversity of forested landscapes of southern Australia. Flammable Australia, the fire regimes and biodiversity of a continent. (ed. by W.J. Bradstock Ra, Gill Am ), pp. 351-369. Cambridge University Press, Cambridge.

Haslem, A., Kelly, L.T., Nimmo, D.G., Watson, S.J., Kenny, S.A., Taylor, R.S., Avitabile, S.C., Callister, K.E., Spence-Bailey, L.M., Clarke, M.F. \& Bennett, A.F. (2011) Habitat or fuel? Implications of long-term, post-fire dynamics for the development of key resources for fauna and fire. Journal of Applied Ecology, 48, 247-256.

Hutchinson, M.F. (2004) ANUSPLIN Version 4.3. Fenner School of Environment and Society, Australian National University. 
514

515

Johnson, E.A. \& Gutsell, S.L. (1994) Fire frequency models, methods and interpretations. Advances in Ecological Research, 25, 239-287.

Johnson, E.A., Miyanishi, K. \& Bridge, S.R.J. (2001) Wildfire regime in the Boreal Forest and the idea of suppression and fuel buildup. Conservation Biology, 15, 1554-1557.

Keeley, J.E., Pausas, J.G., Rundel, P.W., Bond, W.J. \& Bradstock, R.A. (2011) Fire as an evolutionary pressure shaping plant traits. Trends in Plant Science, 16, 406-411.

King, K., Cary, G., Bradstock, R. \& Marsden-Smedley, J. (2013) Contrasting fire responses to climate and management: insights from two Australian ecosystems. Global Change Biology, 19, 1223-1235.

Kraaij, T., Baard, J.A., Cowling, R.M. \& van Wilgen, B.W. (2013) An assessment of historical fire regimes in a poorly-understood, fire-prone ecosystem: eastern coastal fynbos. International Journal of Wildland Fire, 22, 277-287.

Krawchuk, M. \& Moritz, M. (2011) Constraints on global fire activity vary across a resource gradient. Ecology, 92, 121-132.

Legendre, P. (1993) Spatial autocorrelation: trouble or a new paradigm? Ecology, 74, 16591673.

Lehmann, C.E.R., Archibald, S.A., Hoffmann, W.A. \& Bond, W.J. (2011) Deciphering the distribution of the savanna biome. New Phytologist, 191, 197-209.

Lenihan, J.M., Bachelet, D., Neilson, R.P. \& Drapek, R. (2008) Response of vegetation distribution, ecosystem productivity, and fire to climate change scenarios for California Climatic Change, 87, (Suppl 1) :S215-S230.

Letnic, M. \& Dickman, C.R. (2006) Boom means bust: interactions between the El Nino/Southern Oscillation (ENSO), rainfall and the processes threatening mammal species in arid Australia. Biodiversity and Conservation, 15, 3847-3880.

Matthews, S., Sullivan, A.L., Watson, P. \& Williams, R.J. (2012) Climate change, fuel and fire behaviour in a eucalypt forest. Global Change Biology, 18, 3212-3223.

McCarthy, M.A. (2007) Bayesian methods for ecology. Cambridge University Press, Melbourne, Australia.

McCarthy, M.A., Gill, A.M. \& Bradstock, R.A. (2001) Theoretical fire-interval distributions. International Journal of Wildland Fire, 10, 73-77.

Mills, A.J., Milewski, A.V., Fey, M.V., Grongroft, A., Peterson, A. \& Sirami, C. (2012) Constraint on woody cover in relation to nutrient content of soils in western southern Africa. Oikos, 122, 136-148.

Moritz, M., Keeley, J., Johnson, E. \& Schaffner, A. (2004) Testing a basic assumption of shrubland fire management: does the hazard of burning increase with the age of fuels? . Frontiers in Ecology and The Environment, 2, 67-72.

Moritz, M.A. (1997) Analyzing extreme disturbance events: fire in Los Padres National Forest. Ecological Applications, 7, 1252-1262.

Moritz, M.A., Moody, T.J., Miles, L.J., Smith, M.M. \& de Valpine, P. (2009) The fire frequency analysis branch of the pyrosatistics tree: sampling decisions and censoring in fire interval data. Environmental and Ecological Statistics, 16, 271-289.

Noble, J.C. \& Bradstock, R.A. (1989) Mediterranean Landscapes in Australian Mallee Ecosystems and their Management CSIRO, Melbourne.

NRIC (1991) Australian digital soils atlas. In: Australian Soils (ed. N.R.I. Centre). Bureau of Rural Sciences

O'Donnell, A., Boer, M., McCaw, W. \& Grierson, P. (2011a) Vegetation and landscape connectivity control wildfire intervals in unmanaged semi-arid shrublands and woodlands in Australia. Journal of Biogeography, 38, 112-124. 
562

563

564

565

566

567

568

569

570

571

572

573

574

575

576

577

578

579

580

581

582

583

584

585

586

587

588

589

590

591

592

593

594

595

596

597

598

599

600

601

602

603

604

605

606

607

608

609

O'Donnell, A., Boer, M., McCaw, W. \& Grierson, P. (2011b) Climatic anomolies drive wildfire occurrence and extent in semi-arid shrublands and woodlands of southwest Australia. Ecosphere, 2(11), 127.

Ojeda, F., Pausas, J.G. \& Verdu, M. (2010) Soil shapes community structure through fire. Oecologia, 163, 729-735.

Paoli, G.D., Curran, L.M. \& Slik, J.W.F. (2008) Soil nutrients affect spatial patterns of aboveground biomass and emergent tree density in southwestern Borneo. Oecologia, 155, 287-299.

Pausas, J. \& Bradstock, R. (2007) Fire persistence traits of plants along a productivity and disturbance gradient in mediterranean shrublands of south-east Australia. Global Ecology and Biogeography, 16, 330-340.

Pausas, J. \& Paula, S. (2012) Fuel shapes the fire-climate relationship: evidence from Mediterranean ecosystems. Global Ecology and Biogeography, 21, 1074-1082.

Polakow, D.A. \& Dunne, T.T. (1999) Modelling fire-return interval T: stochasticity and censoring in the two-parameter Weibull model. Ecological Modelling, 121, 79-102.

Russell-Smith, J., Yates, C., PJ, W., Smith, R., Craig, R., Allan, G., Thackway, R., Frakes, R., Cridland, S., Meyer, M. \& Gill, A. (2007) Bushfires 'down under': patterns and implications of contemporary Australian landscape burning. International Journal of Wildland Fire, 16, 361-377.

Sage, R.F., Wedin, D.A. \& Li, M. (1999) The Biogeography of C4 Photosynthesis: patterns and controlling factors. C4 Plant Biology (ed. by R.F. Rowan and R.K. Monson), pp. 313-389. Academic Press, San Diego, California.

Spiegelhalter, D.J., Best, N.G., Carlin, B.P. \& van der Linde, A. (2002) Bayesian measures of model complexity and fit. Journal of the Royal Statistical Society Series B-Statistical Methodology, 64, 583-616.

Suppiah, R., Hennessy, K.J., Whetton, P.H., McInnes, K., Macadam, I., Bathols, J., Ricketts, J. \& Page, C.M. (2007) Australian climate change projections derived from simulations performed for the IPCC $4^{\text {th }}$ Assessment Report. Australian Meteorological Magazine, 56, 131-152.

Thomas, A., O'Hara, B., Ligges, U. \& Sturtz, S. (2006) Making BUGS open. R News, 6, 1217.

van Wilgen, B., Forsyth, G., De Klerk, H., Das, S., Khuluse, S. \& Schmitz, P. (2010) Fire management in Mediterranean-climate shrublands: a case study from the Cape fynbos, South Africa. Journal of Applied Ecology, 47, 631-638.

Wang, S., Heckathorn, S.A., Wang, X. \& Philpott, S.M. (2012) A meta-analysis of plant physiological and growth responses to temperature and elevated $\mathrm{CO}_{2}$. Oecologia, 169, $1-13$.

Wasson, R.J. (1989) Landforms. Mediterranean landscapes in Australia: mallee ecosystems and their management (ed. by N. I.R. and R.A. Bradstock). CSIRO Australia, Melbourne.

Westbrooke, M.E., Miller, J.D. \& Kerr, M.K.C. (1998) The vegetation of the Scotia 1:100 000 map sheet, western New South Wales. Cunninghamia, 5, 665-684.

Willson, A. (1999) Tarawi Nature Reserve: Fire Management Plan. New South Wales National Parks and Wildlife Service, Hurstville.

Wintle, B.A., Elith, J. \& Potts, J.M. (2005) Fauna habitat modelling and mapping: a review and case study in the Lower Hunter Central Coast region of NSW. Austral Ecology, 30, 719-738. 


\section{SUPPORTING INFORMATION}

611 Additional Supporting Information may be found in the online version of this article:

612 Appendix S1: Decadal sequence of fire history maps across the study area since 1930 (Fig. S1-S9)

613 Appendix S2: Maps vegetation type at each random sampling point in each park or reserve included 614 in the analysis (Fig. S10-S18)

615 Appendix S3: Cumulative probability curves of fire interval distributions, based on empirical fire 616 history data (Fig. S19)

617 


\section{BIOSKETCH}

619 The research team represents a collaborative venture between government and academic

620 researchers funded by an Australian Research Council Linkage grant. The team is devoted to 621 understanding the role of fire in determining ecological diversity in dry, shrub-dominated 622 environments and harnessing such knowledge to improve the management of fire in 623 conservation reserves. The scope of this work includes quantification of fire regime patterns 624 and processes, the ecology and population genetics of key plant and animal taxa and 625 application of population models to explore fire management scenarios that enhance 626 population viability.

627

628 Author contributions: All authors contributed to conceiving the ideas; R.K.G. collected the 629 data; R.K.G, T.P. and R.A.B. analysed the data; and R.K.G. and R.A.B. led the writing.

630 
631 Table 1 Summary of the relative proportion of the landscape that each vegetation/soil 632 complex occupies, within the dry $(<300 \mathrm{~mm} / \mathrm{yr})$ and wet $(>300 \mathrm{~mm} / \mathrm{yr})$ regions of the study 633 area. Bold values indicate the cases where $>50 \%$ of the landscape is occupied.

\begin{tabular}{lcc}
\hline \multirow{2}{*}{ Vegetation/soil complex } & \multicolumn{2}{c}{ Relative proportion of the landscape (\%) } \\
\cline { 2 - 3 } & $<300 \mathbf{m m} / \mathbf{y r}$ & $>\mathbf{3 0 0 m m} / \mathbf{y r}$ \\
\hline Red sand/ Mallee woodlands & $\mathbf{6 8 . 1 1}$ & 3.31 \\
Yellow sand/ Mallee woodlands & 11.62 & 20.08 \\
Red sand/Mallee heathlands & 5.28 & 14.22 \\
Yellow sand/ Mallee heathlands & 14.99 & $\mathbf{6 2 . 3 9}$ \\
\hline
\end{tabular}

634

635

636 
637 Table 2 Summary of the proportion of censored fire intervals across vegetation, sand and 638 rainfall categories, included in analyses.

639

\begin{tabular}{ccccc}
\hline \multirow{2}{*}{ Rainfall } & \multicolumn{2}{c}{ Mallee Woodlands } & \multicolumn{2}{c}{ Mallee Heathlands } \\
\cline { 2 - 5 } & Red sand & Yellow sand & Red sand & Yellow sand \\
\hline 200 & 90.84 & 92.47 & 0.00 & 0.00 \\
300 & 56.03 & 85.22 & 45.45 & 67.48 \\
400 & 100.00 & 80.93 & 0.00 & 49.74 \\
500 & 0.00 & 100.00 & 0.00 & 0.00 \\
\hline
\end{tabular}

640 
641 Table 3 Estimated Weibull parameters, b (the fire interval, in years, that will be exceeded ca. 37\% of the time) and c, (a measure of the 642 dependence of fire intervals on fuel age) for each of the soil, vegetation, and rain categories in the study region in south-eastern Australia, 643 including the mean, standard deviation (Std. Dev.), the median, upper (97.5 percentile) and lower (2.5 percentile) $95 \%$ credible intervals. The parameter 644 estimate is considered significant at the $p=0.05$ level when the $95 \%$ credible intervals (CIs) do not overlap 0 . Significant differences at the $p=0.05$ level 645 between combinations of soil, vegetation and/or rainfall occur when 95\% CIs do not overlap each other (e.g. the lower CI of $x>$ upper CI of y). Different 646 superscript letters indicate significant differences in parameter estimates among classes at the $\mathrm{p}=0.05$ level.

\begin{tabular}{|c|c|c|c|c|c|c|c|}
\hline \multicolumn{3}{|c|}{ Model Parameters } & \multirow{2}{*}{$\begin{array}{c}\text { Mean } \\
509.000\end{array}$} & \multirow{2}{*}{$\begin{array}{c}\text { Std. Dev. } \\
119.100\end{array}$} & \multirow{2}{*}{$\begin{array}{c}\text { Lower CI (2.5pc) } \\
318.600\end{array}$} & \multirow{2}{*}{$\begin{array}{l}\text { Median } \\
494.700\end{array}$} & \multirow{2}{*}{$\begin{array}{r}\text { Upper CI (97.5pc) } \\
783.000 \quad 647\end{array}$} \\
\hline \multirow{9}{*}{ Red Sand } & \multirow{4}{*}{$\begin{array}{c}\text { Mallee } \\
\text { woodland }\end{array}$} & b-param. $(200 \mathrm{~mm} \text { rain })^{\mathrm{a}}$ & & & & & \\
\hline & & b-param. $(300 \mathrm{~mm} \text { rain })^{\mathrm{b}}$ & 191.200 & 36.590 & 130.500 & 187.400 & 272.300 \\
\hline & & b-param. $(400 \mathrm{~mm} \text { rain })^{\mathrm{d}, \mathrm{e}}$ & 73.370 & 18.590 & 44.020 & 71.010 & 116.400 \\
\hline & & c-param & 1.020 & 0.047 & 0.930 & 1.020 & 1.113 \\
\hline & \multirow{5}{*}{$\begin{array}{c}\text { Mallee } \\
\text { heathland }\end{array}$} & b-param. $(300 \mathrm{~mm} \text { rain })^{\mathrm{a}}$ & 632.000 & 225.600 & 312.500 & 591.800 & 1182.000 \\
\hline & & b-param. $(400 m m \text { rain })^{a}$ & 422.100 & 138.600 & 221.500 & 398.600 & 756.600 \\
\hline & & b-param. $(500 m m \text { rain })^{a, b}$ & 282.700 & 87.350 & 154.900 & 268.300 & 492.400 \\
\hline & & b-param. $(600 m m \text { rain })^{a, b}$ & 190.000 & 56.990 & 105.900 & 180.500 & 326.900 \\
\hline & & c-param ${ }^{\mathrm{x}, \mathrm{y}}$ & 1.164 & 0.073 & 1.027 & 1.164 & 1.312 \\
\hline \multirow{8}{*}{ Yellow Sand } & \multirow{4}{*}{$\begin{array}{c}\text { Mallee } \\
\text { woodland }\end{array}$} & b-param. $(300 m m \text { rain })^{a, b}$ & 468.400 & 145.200 & 252.000 & 444.400 & 813.000 \\
\hline & & b-param. $(400 \mathrm{~mm} \text { rain })^{\mathrm{b}, \mathrm{c}}$ & 225.400 & 55.650 & 137.600 & 217.400 & 353.600 \\
\hline & & b-param. $(500 \mathrm{~mm} \text { rain })^{\mathrm{b}, \mathrm{c}}$ & 109.900 & 25.780 & 68.560 & 106.900 & 169.300 \\
\hline & & c-param $\mathrm{x}, \mathrm{y}$ & 1.138 & 0.065 & 1.014 & 1.137 & 1.267 \\
\hline & \multirow{4}{*}{$\begin{array}{c}\text { Mallee } \\
\text { heathland }\end{array}$} & b-param. $(300 m m \text { rain })^{\mathrm{a}, \mathrm{b}}$ & 324.200 & 46.370 & 243.900 & 321.100 & 425.200 \\
\hline & & b-param. $(400 \mathrm{~mm} \text { rain })^{\mathrm{c}, \mathrm{d}}$ & 117.600 & 12.380 & 95.530 & 117.000 & 143.800 \\
\hline & & b-param. $(500 \mathrm{~mm} \text { rain })^{\mathrm{e}}$ & 42.950 & 5.388 & 33.480 & 42.540 & 54.380 \\
\hline & & c-param & 1.193 & 0.028 & 1.139 & 1.192 & 1.247 \\
\hline
\end{tabular}




\section{FIGURES}

650 Fig. 1 Location of the Mediterranean climate region of south eastern Australia, with the

651 National Parks and Nature Reserves included in the study, classified by soil type. Grid 652 reference datum is GDA 1994, Lambert Conformal Conic projection.

653 Fig. 2 Mean estimate of Weibull parameter $b$ (the length of the fire interval that will be 654 exceeded ca. 37\% of the time, in years) for each combination of sand and vegetation type 655 (mallee woodlands, M.W. and mallee heathlands, M.H.) for the rainfall categories in which 656 they occur. Error bars represent 95\% credible intervals. Different superscript letters indicate 657 significant differences in parameter estimates among classes at the $\mathrm{p}=0.05$ level.

658 Fig. 3 Weibull cumulative mortality functions for each combination of sand and vegetation 659 type (mallee woodlands, M.W. and mallee heathlands, M.H.) for the rainfall categories in 660 which they occur, based on the Weibull parameter estimates (Table 2). The mortality function 661 describes the probability that a fire will occur before or at time t.

662 Fig. 4 Weibull hazard functions for each combination of sand and vegetation type (mallee 663 woodlands, M.W. and mallee heathlands, M.H.) for the rainfall categories in which they 664 occur, based on the Weibull parameter estimates (Table 2). The hazard function reflects the 665 influence of TSF on the probability of burning.

666 Mean estimate of Weibull parameter c (the dependence of fire intervals on TSF) for each 667 combination of sand and vegetation type (mallee woodlands, M.W. and mallee heathlands, 668 M.H.). Error bars represent 95\% credible intervals. Different superscript letters indicate 669 significant differences in parameter estimates among classes at the $\mathrm{p}=0.05$ level.

670 
672 Fig. 1

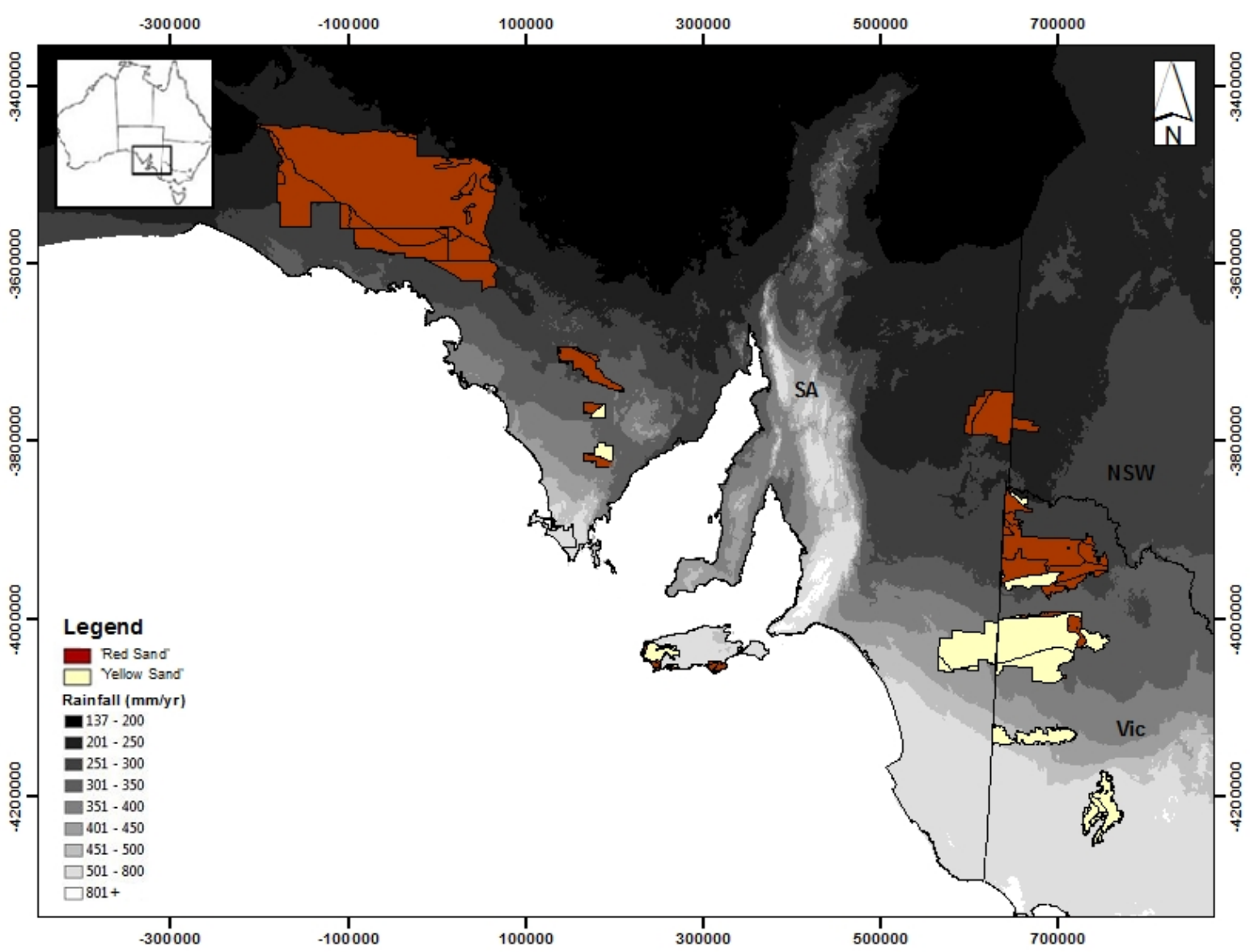

673

674 
675 Fig. 2

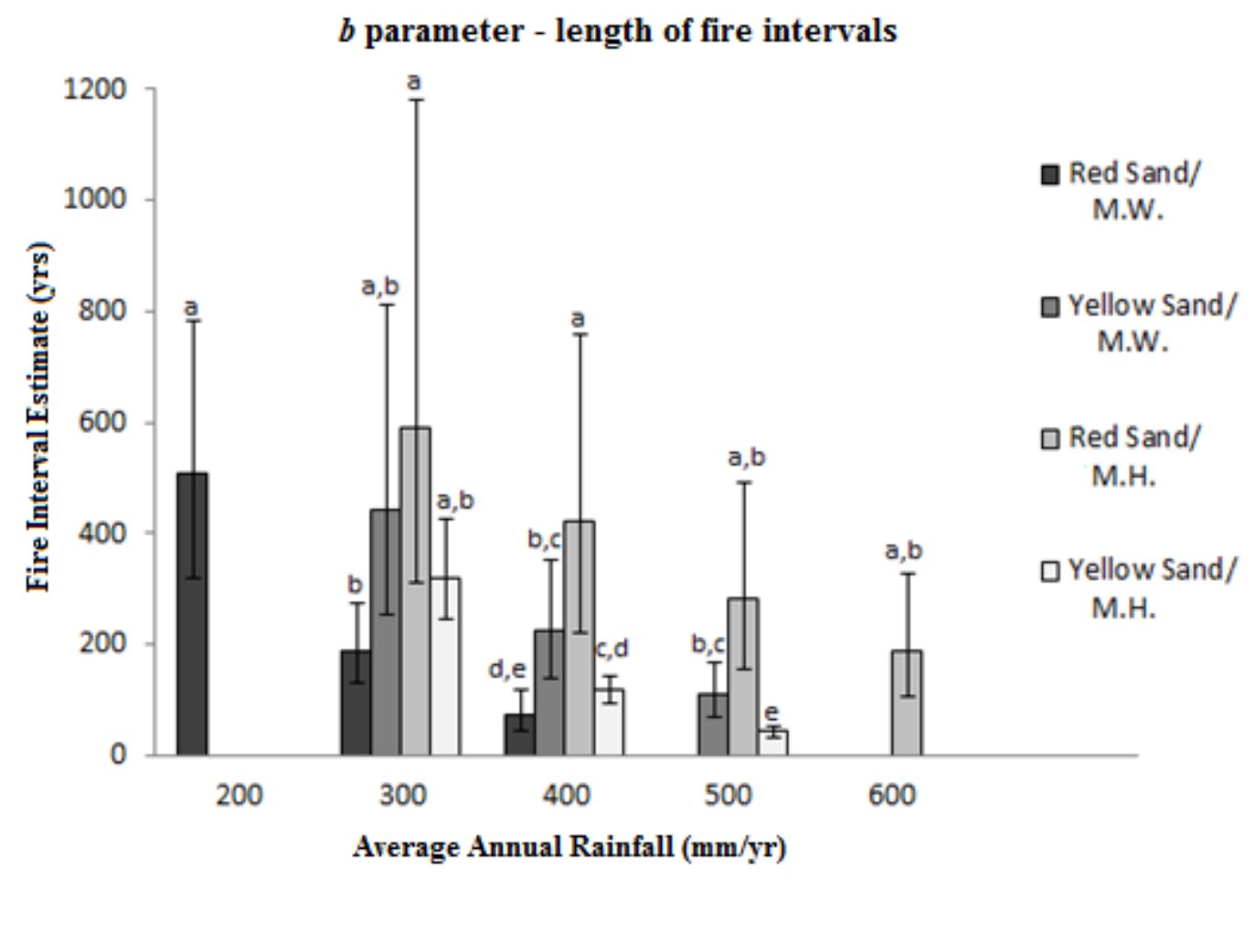

678 
$679 \quad$ Fig. 3

Red Sand/M.W.

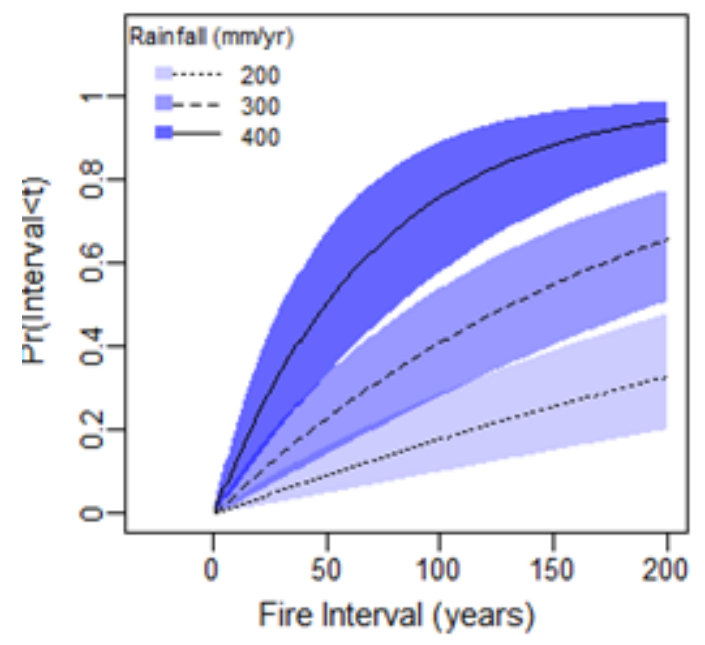

Red Sand/M.H.

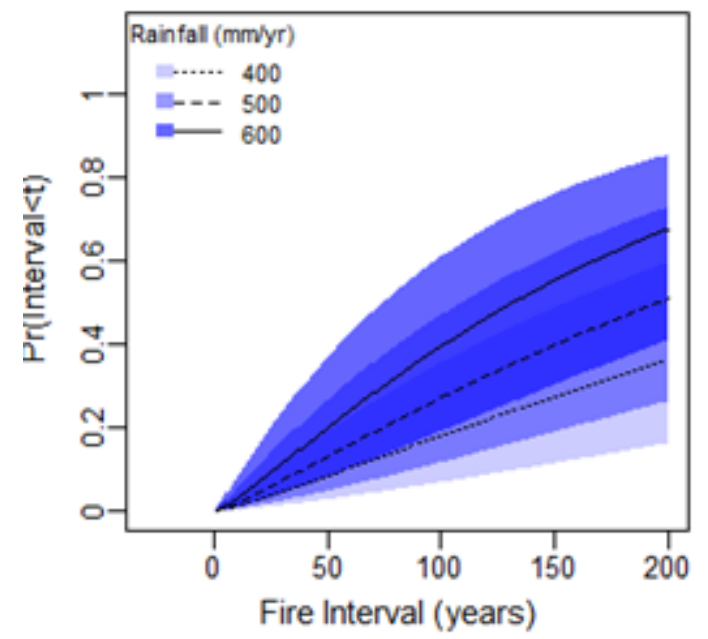

680

681

682

683
Yellow Sand/M.W.

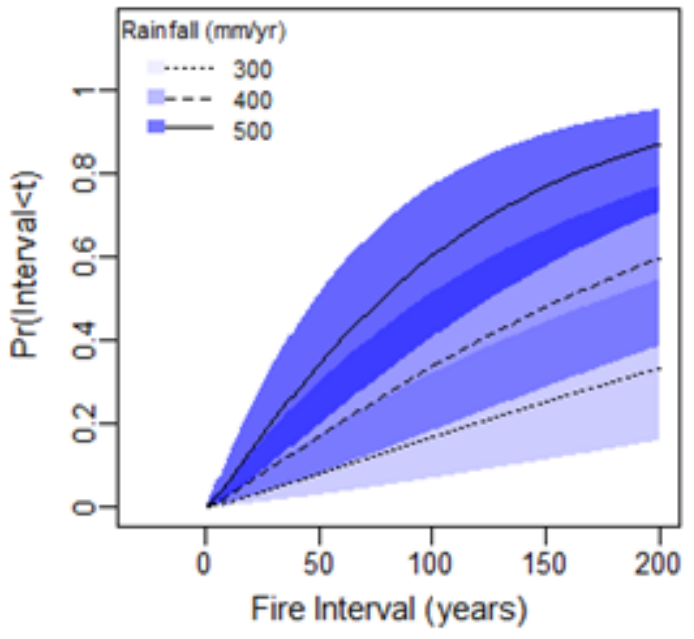

Yellow Sand/M.H.

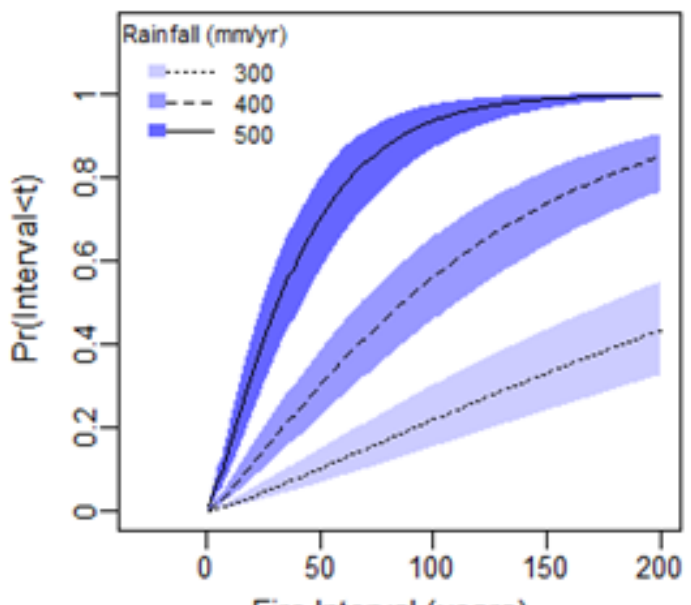

Fire Interval (years) 
$684 \quad$ Fig. 4

Red Sand/M.W.

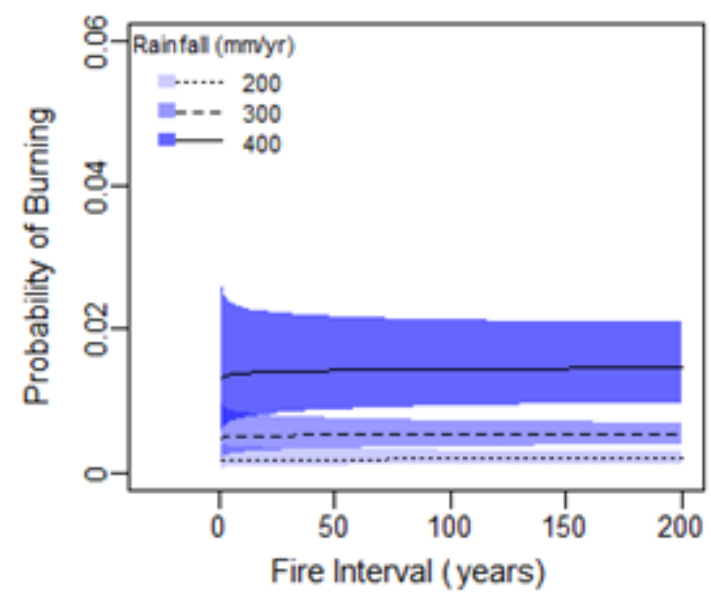

Red Sand/M.H.

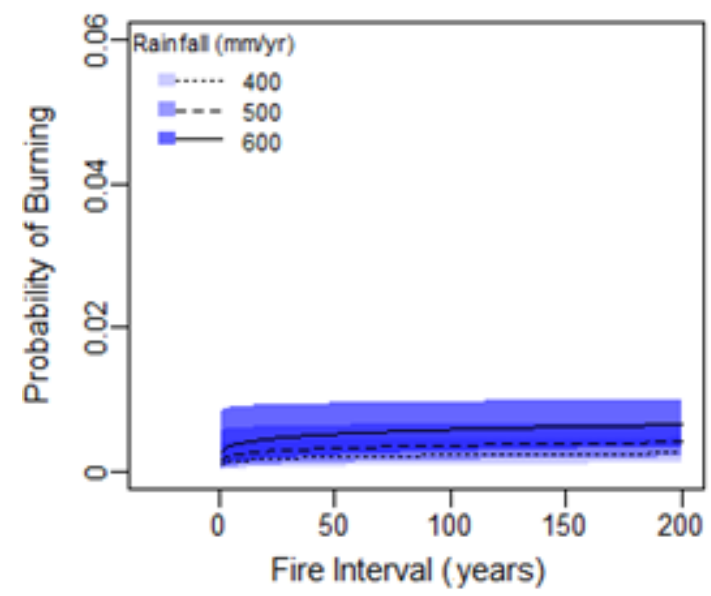

685

686

687

688
Yellow Sand/M.W.

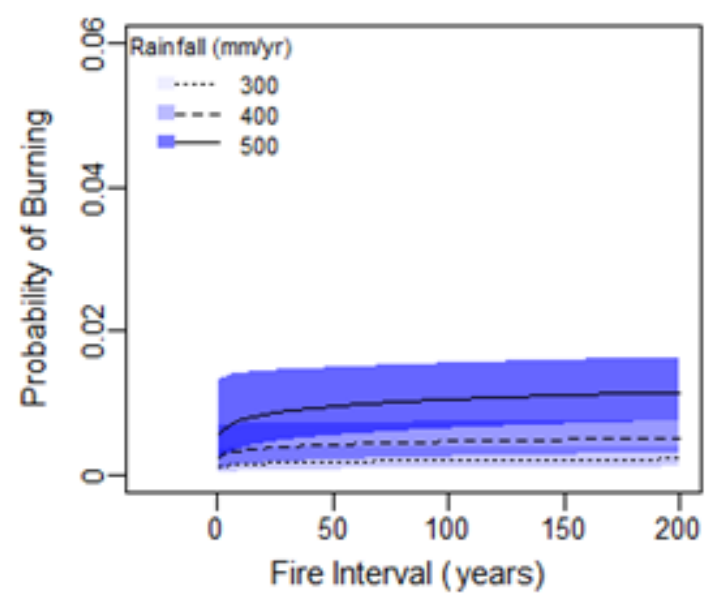

Yellow Sand/M.H.

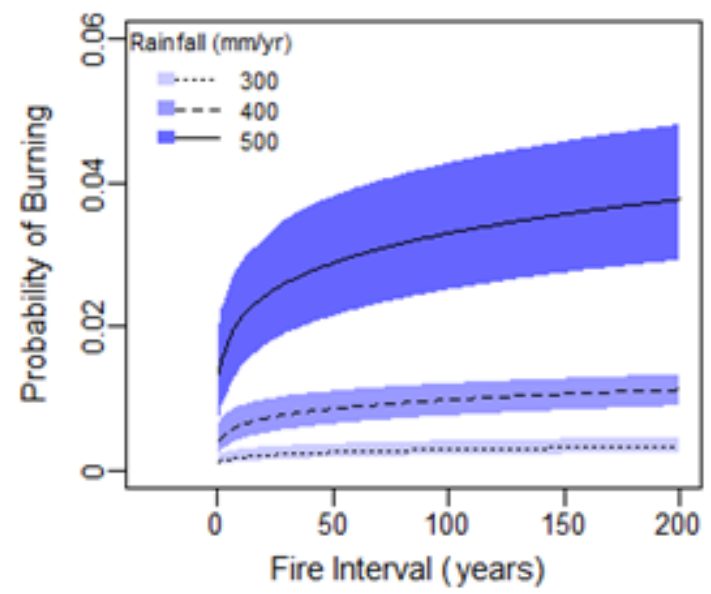

